\title{
Environmental Barrier Coatings for Silicon-Based Ceramics
}

K. N. Lee, D. S. Fox, R. C. Robinson, and N. P. Bansal

NASA Glenn Research Center, Cleveland, OH 44135, USA

\section{Introduction}

Silicon-based ceramics, such as $\mathrm{SiC}$ fiber-reinforced $\mathrm{SiC}(\mathrm{SiC} / \mathrm{SiC})$ ceramic matrix composites (CMC) and monolithic silicon nitride $\left(\mathrm{Si}_{3} \mathrm{~N}_{4}\right)$, are prime candidates for hot section structural components of next generation gas turbine engines. Silicon-based ceramics, however, suffer from rapid surface recession in combustion environments due to volatilization of the silica scale via reaction with water vapor, a major product of combustion $(1,2)$. Therefore, application of silicon-based ceramic components in the hot section of advanced gas turbine engines requires development of a reliable method to protect the ceramic from environmental attack. An external environmental barrier coating $(\mathrm{EBC})$ is considered a logical approach to achieve protection and long-term stability (3).

The first generation $\mathrm{EBC}$ consisted of two layers, mullite $\left(3 \mathrm{Al}_{2} \mathrm{O}_{3}-2 \mathrm{SiO}_{2}\right)$ bond coat and yttria-stabilized zirconia ( $\mathrm{YSZ}, \mathrm{ZrO}_{2}-8$ wt.\% $\mathrm{Y}_{2} \mathrm{O}_{3}$ ) top coat (4). Second generation EBCs, with substantially improved performance compared with the first generation $E B C$, were developed in the NASA High Speed Research-Enabling Propulsion Materials (HSR-EPM) Program (5). They consist of three layers, a silicon first bond coat, a mullite or a mullite + $\mathrm{BSAS}\left(\mathrm{BaO}_{1-\mathrm{x}}-\mathrm{SrO}_{\mathrm{x}}\right.$ $\mathrm{Al}_{2} \mathrm{O}_{3}-2 \mathrm{SiO}_{2}$ ) second bond coat, and a BSAS top coat. The EPM EBCs were applied on $\mathrm{SiC} / \mathrm{SiC}$ $\mathrm{CMC}$ combustor liners in three Solar Turbines (San Diego, CA) Centaur 50s gas turbine engines. The combined operation of the three engines has accumulated over 24,000 hours without failure $\left(\sim 1,250^{\circ} \mathrm{C}\right.$ maximum combustor liner temperature), with the engine in Texaco, Bakersfield, $\mathrm{CA}$, accumulating about 14,000 hours (6).

As the commercialization of Si-based ceramic components in gas turbines is on the horizon, a major emphasis is placed on EBCs for two reasons. First, they are absolute necessity for the protection of Si-based ceramics from water vapor. Second, they can enable a major enhancement in the performance of gas turbines by creating temperature gradients with the incorporation of a low thermal conductivity layer. Thorough understanding of current state-of-the-art EBCs will provide the foundation upon which development of future EBCs will be based. Phase stability and thermal conductivity of EPM EBCs are published elsewhere $(7,8)$ This paper will discuss the chemical/environmental durability and silica volatility of EPM EBCs and their impact on the coating's upper temperature limit.

\section{Experimental}

EBCs were applied at NASA Glenn Research Center by atmospheric pressure plasma spraying onto sintered $a-S i C$ coupons (Hexoloy ${ }^{\mathrm{TM}}$, Carborundum, Niagara Falls, NY) or melt infiltrated

This report is a preprint of an article submitted to a journal for Because of changes that may be made before formal publication, this preprint is made available with the understanding that it will not be cited or reproduced without the permission of the author. 


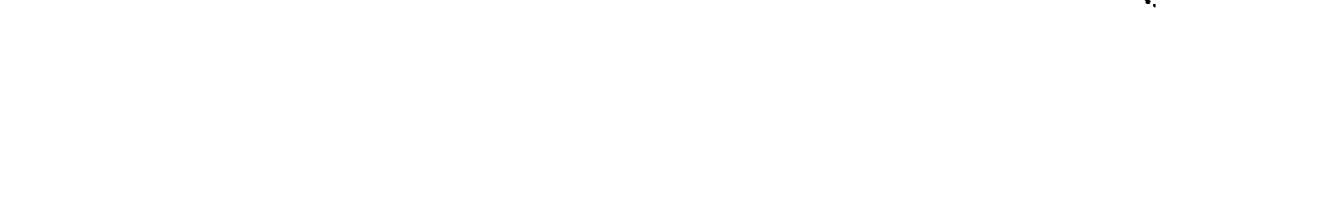
thermally cycled in a water vapor furnace (3). For pressure burner rig (HPBR) tests (2) of EBC-coated MI and volatilization studies, both highstudies of hot pressed EBC coupons in water vapor tests in water vapor were run at 1300 and $1400^{\circ} \mathrm{C}$ in were used. Typically, the thermal cycling lean combustion environments) using an automated $90 \% \mathrm{H}_{2} \mathrm{O}$-balance $\mathrm{O}_{2}$ at 1 atm (simulated were run at $1300^{\circ} \mathrm{C}, 6 \mathrm{~atm}\left(\mathrm{pH}_{2} \mathrm{O} \sim 0.6 \mathrm{~atm}\right)$ fuel thermal cycling furnace. The HPBR tests sec. Water vapor thermogravimetric analysis fuel to air ratio $=0.065$, and gas velocity $\sim 24 \mathrm{~m} /$ $50 \% \mathrm{H}_{2} \mathrm{O}$-balance $\mathrm{O}_{2}$ at $1 \mathrm{~atm}$ (simulated lean was conducted at $1200,1300,1400$ and $1500^{\circ} \mathrm{C}$ in mounted in epoxy, polished to $1 \mu \mathrm{m}$ using diamondion environments). Tested samples were electron microscopy (SEM), energy dispersive spection, and examined using scanning analysis (EMPA).

\section{Results and Discussion}

\subsection{Chemical / Environmental Durability}

\subsubsection{BSAS EBC}

BSAS was identified as a promising EBC candidate because of its close CTE match with Sibased ceramics $\left(4 \sim 5 \times 10^{-6} /{ }^{\circ} \mathrm{C}\right)$ and low silica activity $(<0.1)(5)$. It also possesses excellent shows a cross section of BSAS-coated $\mathrm{MI}$, presumably due to the low elastic modulus. Figure 1 $\mathrm{H}_{2} \mathrm{O}$. A thick $(10 \sim 20 \mu \mathrm{m})$ reaction zone and large $\mathrm{h}$ at $1300^{\circ} \mathrm{C}$ with $2 \mathrm{~h}$ furnace cycles in $90 \%$ Analysis by EDS revealed that the reaction zone pores developed at the BSAS/silica interface. amount of $\mathrm{Al}$ and $\mathrm{Ba}$ ( $\mathrm{Sr}$ peak overlapped withthed a high level of $\mathrm{Si}$ and a significant thermally-grown silica and BSAS. The reaction zone, which), suggesting a reaction between Spectroscopy (7), may be benign to coating durability asch is amorphous according to Raman detrimental to the EBC durability is that the porability as long as it remains solid. What is causing EBC delamination. Pores are attributed to continue to grow and eventually coalesce, scale as the scale viscosity is significantly reduced the bubbling of gaseous species through the $\mathrm{Al}(9)$. Gaseous species include $\mathrm{CO}, \mathrm{CO}_{2}$, or $\mathrm{Si}$ due to contamination by oxides of $\mathrm{Ba}, \mathrm{Sr}$, and Therefore, the BSAS-silica chemical incompatibility $)_{4}$, reaction products of oxidation of SiC. BSAS unsuitable as an $\mathrm{EBC}$ when applied directly on Si-based ratures as low as $1200^{\circ} \mathrm{C}$ makes

\subsubsection{Mullite+BSAS/BSAS EBC}


to a small fraction of the EBC/substrate interface in contact with the BSAS. The BSAS-silica reaction is enhanced as the kinetics of silica formation and BSAS-silica reaction increase with temperature. At $\mathrm{T}>1400^{\circ} \mathrm{C}$, the BSAS-silica reaction eventually produced a significant amount of low melting $\left(\sim 1300^{\circ} \mathrm{C}\right) \mathrm{Al}_{2} \mathrm{O}_{3}-\mathrm{SiO}_{2}-\mathrm{BaO}-\mathrm{SrO}$ glasses, with subsequent spallation of EBC. The formation of low melting glasses is a key life-limiting factor for the mullite+BSAS/BSAS EBC system.

\subsubsection{Mullite/BSAS EBC}

A mullite/BSAS EBC can be as durable as mullite+BSAS/BSAS EBC at $1300^{\circ} \mathrm{C}$ as shown in Fig. 3a. A major disadvantage of the mullite bond coat compared with the mullite+BSAS bond coat is the difficulty in depositing crack-free mullite. There was a significant batch-to-batch variation in segmental cracks, implying a small margin of error in controlling the coating quality. Segmental cracks provide the path for water vapor and thus cause enhanced degradation (Fig. $3 \mathrm{~b}$ ), leading to reduced EBC life. Residual amorphous mullite and CTE mismatch are believed to be responsible for the segmental cracks (4). The fact that the deposition of residual amorphous mullite is sensitive to process variationfindicates that residual amorphous mullite is key to the variation in segmental cracking. A major advantage of the mullite bond coat compared with the mullite+BSAS bond coat is the absence of low melting glass formation as BSAS-silica reaction is eliminated. In the absence of glass formation, however, BSAS suffers a different type of degradation at $\mathrm{T}>1400^{\circ} \mathrm{C}$. Figures $4 \mathrm{a}$ and $4 \mathrm{~b}$ show cross sections of mullite/BSAS EBC on SiC after $180 \mathrm{~h}$ and $20 \mathrm{~h}$ at $1400^{\circ} \mathrm{C}\left(20 \mathrm{~h}\right.$ thermal cycles) and $1500^{\circ} \mathrm{C}$ (isothermal), respectively, in air. The BSAS surface began to show degradation at $1400^{\circ} \mathrm{C}$, forming a porous structure (Fig. $4 \mathrm{a}$ ), which became very severe at $1500^{\circ} \mathrm{C}$ as the porous structure spread over the entire BSAS layer (Fig. 4b). The cause of the degradation is not fully understood. The formation of a porous structure is likely to be a key life-limiting factor at $\mathrm{T}>1400^{\circ} \mathrm{C}$.

\subsection{Silica Volatility}

Figure 5 shows the plots of weight change versus time for uncoated and $\mathrm{EBC}$-coated $\mathrm{SiC}$ at $1300^{\circ} \mathrm{C}$ in the HPBR ( 6 atm, $\mathrm{pH}_{2} \mathrm{O} \sim 0.6 \mathrm{~atm}$, gas velocity $\sim 24 \mathrm{~m} / \mathrm{sec}$, fuel to air ratio $=0.065$ ). Each datum in the plots represents one thermal cycle since the test was interrupted to measure the weight. The linear weight loss of uncoated CVD SiC and MI was due to the volatilization of silica by water vapor. Mullite+BSAS/BSAS- and mullite/BSAS-coated MI also showed a slight weight loss. Cross sections of mullite+BSAS/BSAS- and mullite/BSAS-coated MI showed excellent adherence and minimal oxidation, implying that the weight loss was mainly due to the volatilization of silica from BSAS.

Figure 6 shows the plots of weight change versus time for hot pressed monolithic BSAS exposed to $50 \% \mathrm{H}_{2} \mathrm{O}$-balance $\mathrm{O}_{2}$ at $1200-1500^{\circ} \mathrm{C}$ in thermogravimetry ( 1 atm, gas velocity $=4.4$ $\mathrm{cm} / \mathrm{sec}$ ). Linear weight loss was observed at all temperatures with the rate increasing with temperature. The weight loss rate at $1300^{\circ} \mathrm{C}$ was converted to the weight loss rate at the HPBR condition ( $6 \mathrm{~atm}, \mathrm{pH}_{2} \mathrm{O}=0.6 \mathrm{~atm}, \mathrm{~V}_{\mathrm{g}}=24 \mathrm{~m} / \mathrm{sec}$ ) using the following silica volatility equation, which assumes $\mathrm{Si}(\mathrm{OH})_{4}$ as the sole reaction product (2),

$$
\text { Volatility } \propto \mathrm{V}_{\mathrm{g}}^{0.5}\left(\mathrm{pH}_{2} \mathrm{O}\right)^{2} / \mathrm{P}_{\text {tot }} 0.5
$$


where $\mathrm{V}_{\mathrm{g}}$ is the gas velocity, $\mathrm{pH}_{2} \mathrm{O}$ is the water vapor pressure, and $\mathrm{P}_{\text {tot }}$ is the total pressure. The converted rate from the themogravimetry measurements $\left(3.3 \times 10^{-3} \mathrm{mg} / \mathrm{cm}^{2}-\mathrm{h}\right)$ agreed fairly well with the rate determined using the HPBR $\left(\sim 6 \times 10^{-3} \mathrm{mg} / \mathrm{cm}^{2}-\mathrm{h}\right)$. Projected recession of BSAS, after $1000 \mathrm{~h}$ at $6 \mathrm{~atm}, \mathrm{pH}_{2} \mathrm{O}=0.6 \mathrm{~atm}$, and $\mathrm{V}_{\mathrm{g}} \sim 24 \mathrm{~m} / \mathrm{sec}$, from equation (1) and the silica volatility data from thermogravimetry was 4,18 , and $72 \mu \mathrm{m}$, at 1300,1400 , and $1500^{\circ} \mathrm{C}$, respectively. The recession will be even higher in typical engines that run at higher pressure and gas velocity. Based on BSAS thickness of $\sim 250 \mu \mathrm{m}(\sim 10$ mil), typical of current YSZ TBCs in aero gas turbines, the volatility of BSAS will be another key life-limiting factor for over several thousand hours of operation at $\mathrm{T}>1400^{\circ} \mathrm{C}$.

\section{Conclusions}

Chemical/environmental durability and silica volatility all suggest that the upper temperature limit of EBCs based on mullite and BSAS, for several thousand hours of life, is $\sim 1400^{\circ} \mathrm{C}$. Since the temperature drop through the $\mathrm{EBC}$ will lower the temperature at the $\mathrm{EBC} / \mathrm{CMC}$ interface below $1400 \mathrm{C}^{\circ} \mathrm{C}$, the BSAS-silica reaction is not likely to be as critical as BSAS degradation by the formation of a porous structure and silica volatilization at $\sim 1400^{\circ} \mathrm{C}$. The characterization of EBCs under realistic temperature gradients in steam environments is needed to provide more accurate life projections. The further development of EBCs, with higher temperature capability and lower thermal conductivity than today's EBCs, is necessary to realize the full potential of Sibased ceramics in gas turbine engines.

\section{Acknowledgements}

This work was supported by the NASA Ultra Efficient Engine Technology (UEET) Program.

\section{References}

[1] E. J. Opila and R. Hann, J. Am. Ceram. Soc., 80, 197 (1997).

[2] J. L. Smialek, R. C. Robinson, E. J. Opila, D. S. Fox, and N. S. Jacobson, Adv. Composite Mater., 8, 33-45 (1999).

[3] K. N. Lee, H. Fritze, and Y. Ogura, Progress in Ceramic Gas Turbine Development, Vol. 2. Edited by M. van Roode, M. Ferber, and D. W. Richerson, ASME PRESS (in press).

[4] K. N. Lee, Transactions of the ASME, 122, 632 (2000).

[5] K. N. Lee, Surface and Coatings Technology, 133-134, 1 (2000).

[6] H. E. Eaton, G. D. Linsey, E. Y. Sun, K. L. More, J. B. Kimmel, J. R. Price, and N. Miriyala, Proceedings of ASME TurboExpo 2001, New Orleans, Louisiana (2001).

[7] J. I. Eldridge and K. N. Lee, The $25^{\text {th }}$ Annual International Conference on Advanced Ceramics and Structures, Cocoa Beach, FL (2001).

[8] D. Zhu, K. N. Lee, and R. A. Miller, The $25^{\text {th }}$ Annual International Conference on Advanced Ceramics and Structures, Cocoa Beach, FL (2001).

[9] K. N. Lee, J. Am. Ceram. Soc., 81, 3329-32 (1998). 

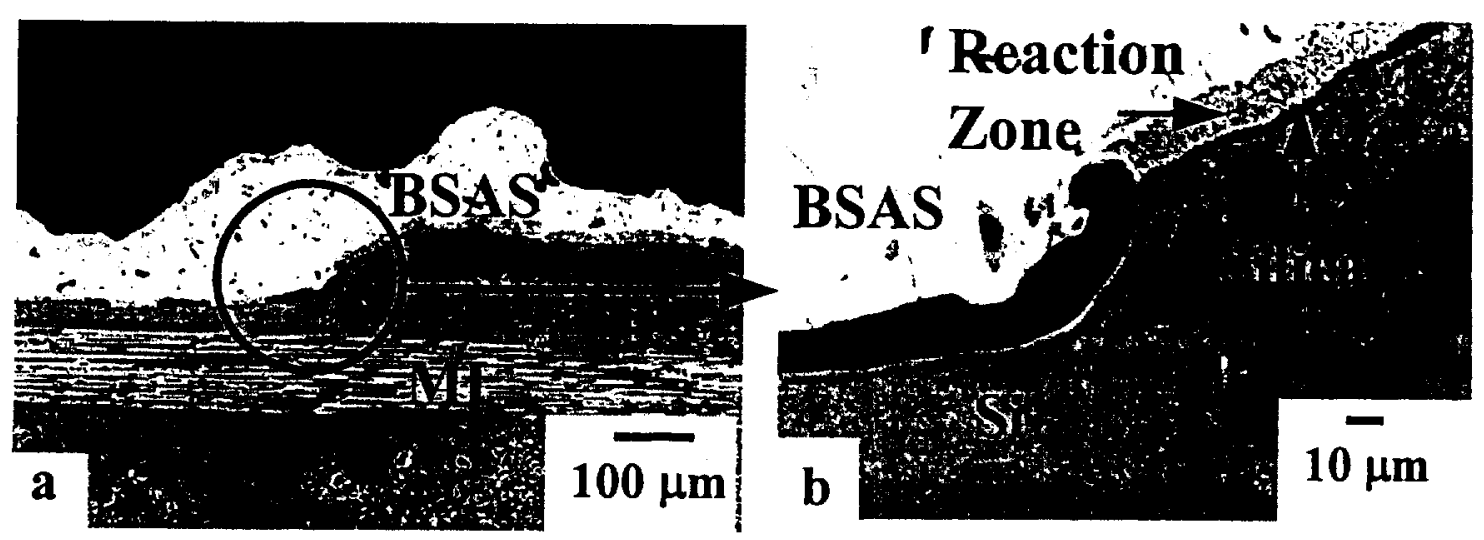

Fig. 1 Cross section of BSAS-coated MI after $100 \mathrm{~h}$ in $90 \% \mathrm{H}_{2} \mathrm{O}$-balance $\mathrm{O}_{2}$ at $1300^{\circ} \mathrm{C}$ with $2 \mathrm{~h}$ furnace cycles

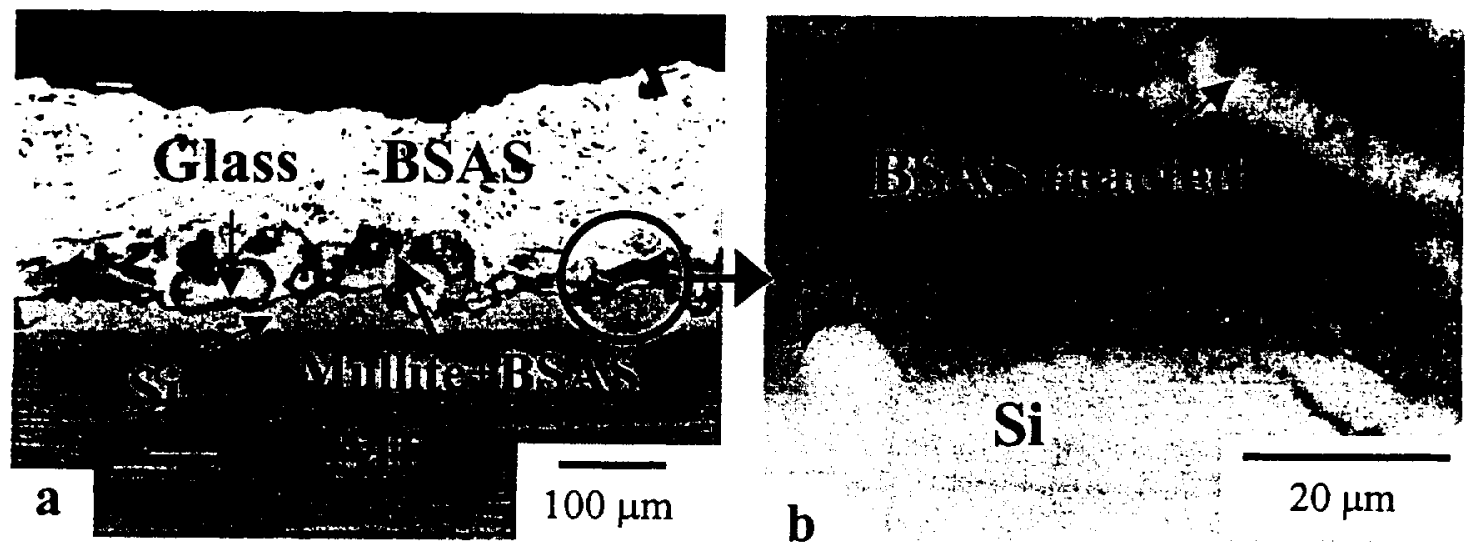

Fig. 2 Cross section of mullite+BSAS/BSAS on MI after $1000 \mathrm{~h}$ in $90 \% \mathrm{H}_{2} \mathrm{O}$-balance $\mathrm{O}_{2}$ at $1300^{\circ} \mathrm{C}$ with $\mathrm{lh}$ furnace cycles
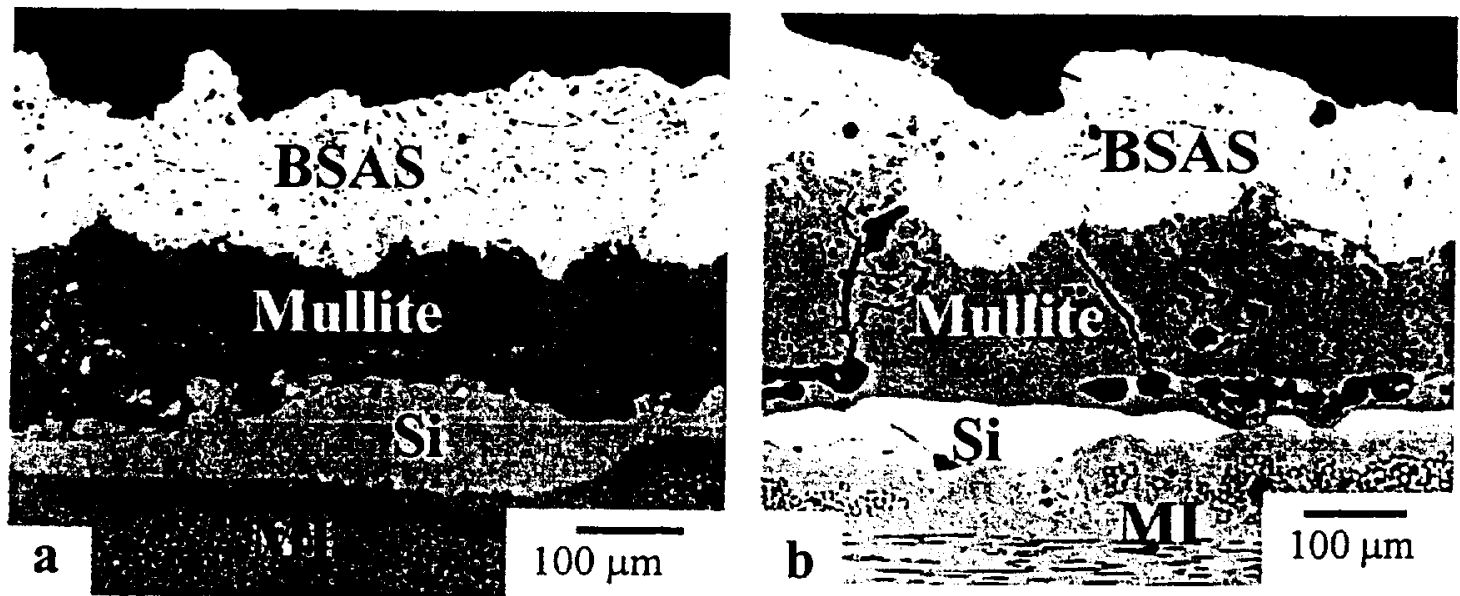

Fig. 3 Cross sections of mullite/BSAS on MI after $1000 \mathrm{~h}$ in $90 \% \mathrm{H}_{2} \mathrm{O}$-balance $\mathrm{O}_{2}$ at $1300^{\circ} \mathrm{C}$ with $1 \mathrm{~h}$ furnace cycles ( $\mathrm{a}$ and $\mathrm{b}$ are from two different batches of coatings) 

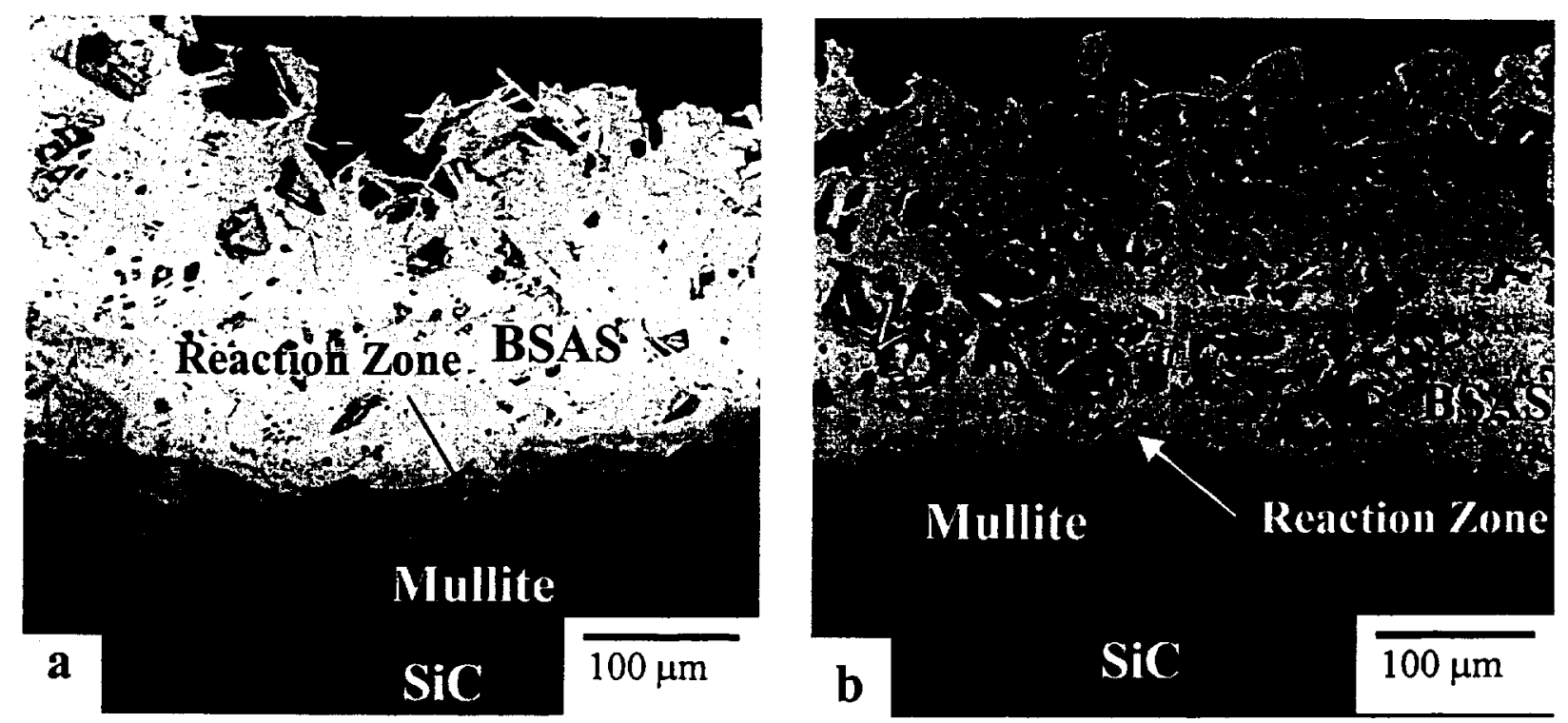

Fig. 4 Cross section of mullite/BSAS on SiC after thermal exposures in air. The reaction zone is a diffusion zone between mullite and BSAS.

a: $180 \mathrm{~h}, 1400^{\circ} \mathrm{C}-20 \mathrm{~h}$ furnace cycles; b: $20 \mathrm{~h}, 1500^{\circ} \mathrm{C}$ isothermal furnace

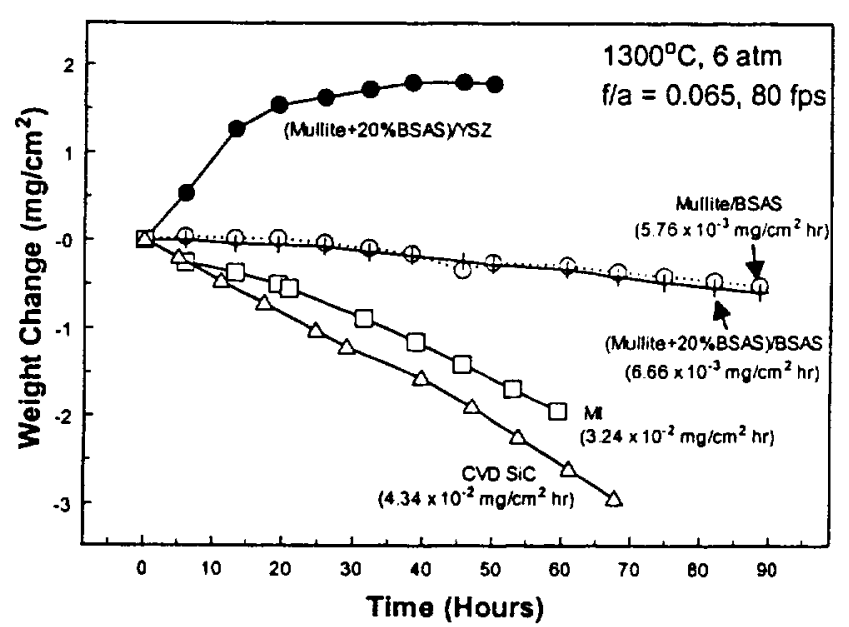

Fig. 5 The plots of weight change vs. time for uncoated and $\mathrm{EBC}$-coated $\mathrm{SiC}$ in high pressure burner rig $\left(1300^{\circ} \mathrm{C}, 6 \mathrm{~atm}, \mathrm{pH}_{2} \mathrm{O}\right.$ $\sim 0.6 \mathrm{~atm}$, gas velocity $\sim 24 \mathrm{~m} / \mathrm{sec}$, fuel to air ratio $=0.065$ )

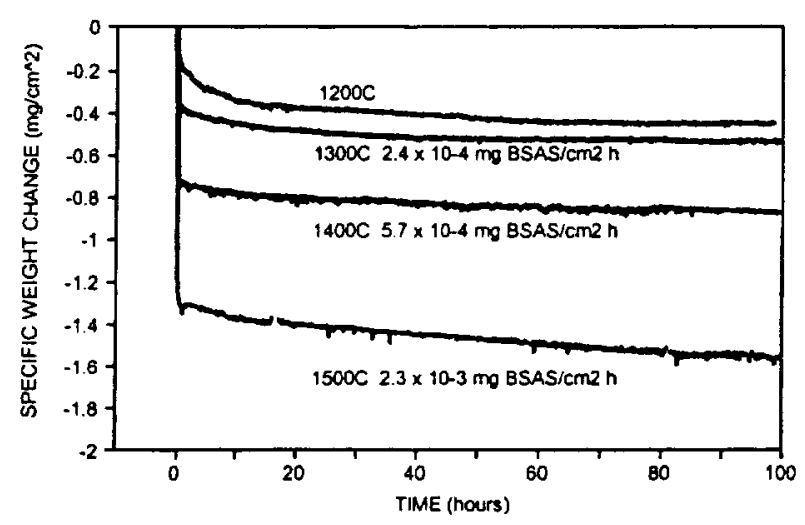

Fig. 6 The plots of weight change vs. time for hot pressed BSAS in TGA $\left(1200^{\circ} \mathrm{C}-1500^{\circ} \mathrm{C}, 1 \mathrm{~atm}, \mathrm{pH}_{2} \mathrm{O}=0.5 \mathrm{~atm}\right.$, gas velocity $=4.4 \mathrm{~cm} / \mathrm{sec}$ ) 